\title{
Interactions between polyps of Aurelia aurita and planktonic larvae of scyphozoans: an experimental study
}

\author{
F. Gröndahl
}

Kristineberg Marine Biological Station, S-450 34 Fiskebäckskil, Sweden

\begin{abstract}
Predation by polyps of the scyphozoan Aurelia aurita (L.) on planula larvae of their own species and on planulae of the scyphozoan Cyanea capillata (L.) was studied in laboratory experiments. Transplant experiments in the field tested whether high densities of established A. aurita polyps could affect the recruitment of planktonic larvae and if interactions between the polyps occur. More planula larvae of $C$. capillata than of $A$. aurita were eaten by the polyps. The transplant experiments showed that dense covers of $A$. aurita polyps can affect recruitment of planulae and other planktonic larvae to hard-bottom communities. The most likely explanation is predation on the larvae. Interactions indicating competition for space or food between already established polyps and settling planulae were observed. Mortality among established polyps was greater at high than at low densities. Planula larvae of both $A$. aurita and $C$. capillata showed an increased rate of metamorphosis in the presence of $A$. aurita polyps in the laboratory experiments.
\end{abstract}

\section{INTRODUCTION}

The scyphozoans are characterized by a life-cycle comprising a sexual planktonic medusa phase and a benthic asexual scyphistoma or polyp phase. Jägersten (1968) and Watzin (1986) pointed out that selection operates at all stages in the life-cycle (larval, juvenile and adult) and emphasized the importance of studying all these stages. The mortality of the polyps and newly released ephyra of Aurelia aurita (L.) and Cyanea capillata (L.) has been discussed by Hernroth \& Gröndahl (1983, 1985a, b), Gröndahl \& Hernroth (1987), and Gröndahl (1988). Mortality during the larval stage of planktonic-benthic life cycles can have a major effect on the abundance of the adult benthic population (Thorson 1950, Mileikovsky 1974). Thus, the mortality of the free-swimming planula larvae and the polyps of A. aurita and C. capillata may be important as a limiting mechanisms in the development of the large interannual variations in the abundance of medusae reported by Möller (1980) and Lindahl \& Hernroth (1983). Predation by benthic predators may be one of the major sources of mortality of planula larvae as well as of other planktonic larvae of benthic marine invertebrates (e.g. Korringa 1941, Thorson 1950, Keough \&
Downes 1982, Cowden et al. 1984, Crowe et al. 1987). Results of a preliminary study by Gröndahl (1988) showed that polyps of $A$. aurita readily prey on planulae of $C$. capillata and that such predation might be of importance for the recruitment of $C$. capillata polyps.

Aurelia aurita is the most common scyphozoan polyp on the Swedish west coast (Gröndahl \& Hernroth 1987 , Gröndahl 1988). The polyps can be described as 'opportunistic' in that they are commonly found on a variety of substrata, e.g. the underside of rocks or the thalli of algae, the tunica of ascidians and the shells of living and dead barnacles. They readily colonize submerged settling tiles of glass, ceramic and plastic. During the period July to October A. aurita polyps may cover large areas of hard-bottom substrata from 1 to $20 \mathrm{~m}$ in depth. The planulae may settle gregariously and densities of 60000 to 400000 polyps $\mathrm{m}^{-2}$ have been observed on the Swedish west coast (Gröndahl 1988).

This paper reports on the effect of Aurelia aurita polyps as predators, both on planulae of Cyanea capillata and on their own planula larvae. The objective of the study was to experimentally test the question: Does the presence of high densities of established polyps affect the recruitment of scyphozoan larvae? 
The results indicate that $A$. aurita polyps prey upon both their own larvae and Cyanea capillata planulae and that the presence of established polyps has a highly significant negative effect on larval settling.

\section{MATERIALS AND METHODS}

Medusae of Aurelia aurita and Cyanea capillata with planula larvae were collected from the mouth of Gullmarsfjorden on the Swedish west coast (Fig. 1) during September 1987. Seaweed Laminaria saccharina (Lamour) with a dense cover of Aurelia aurita polyps was collected from subtidal rock walls at $5 \mathrm{~m}$ depth. The polyps were kept in laboratory aquaria, in running seawater, obtained from $33 \mathrm{~m}$ depth, with salinity 32 to $34 \%$ and temperature ca $14^{\circ} \mathrm{C}$. All material was used within a week.

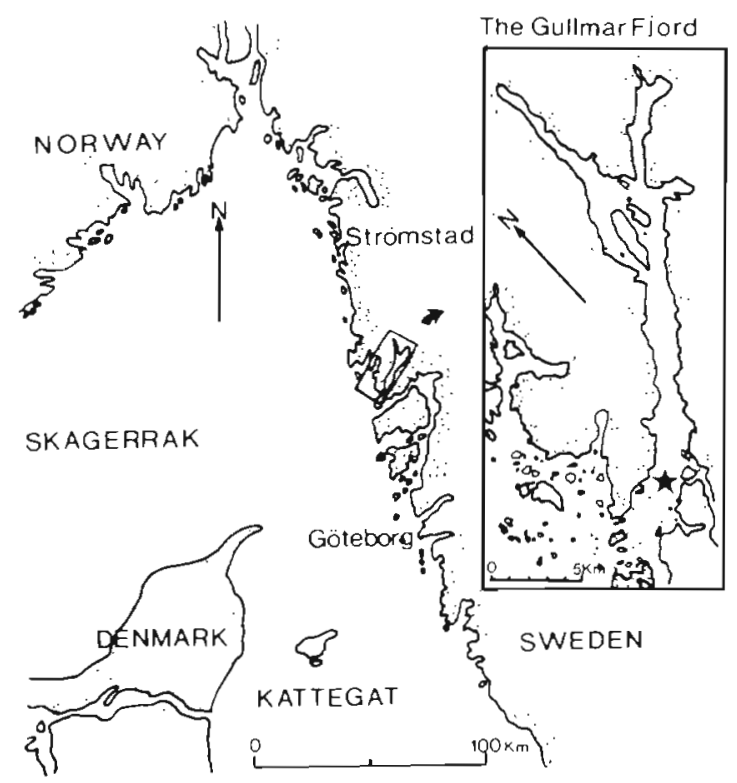

Fig. 1. Location of Gullmarsfjorden, with the sampling area ( $\star$ )

In order to study the feeding behaviour of the polyps, planulae of Aurelia aurita and Cyanea capillata were transferred into Petri dishes containing established $A$. aurita polyps. The feeding rate and the behaviour of the polyps were studied using a stereo microscope.

Predation experiments. Twelve $250 \mathrm{ml}$ beakers were filled with $200 \mathrm{ml}$ of filtered seawater (Millipore 0.45 $\mu \mathrm{m}$, type HA filter). In 6 of the beakers, a piece of Laminaria saccharina $(\mathrm{ca} 2 \times 2 \mathrm{~cm})$, bearing a natural density (50 to $100, \bar{x}=66$ ) of Aurelia aurita polyps without signs of tentacle reduction, was suspended about $20 \mathrm{~mm}$ from the bottom and mounted so that the polyps were pointing downward. The remaining 6 beakers were used as controls and contained pieces of L. saccharina that had been cleaned of $A$. aurita polyps.
In the first experiment, 100 actively swimming planulae of Cyanea capillata were pipetted into each of the 12 beakers. The experiment was run at a temperature of $15^{\circ} \mathrm{C}$ for $24 \mathrm{~h}$ before the water in the beakers was carefully sieved through a $45 \mu \mathrm{m}$ mesh. The piece of seaweed and the beakers were also carefully examined to find settled planulae. The remaining planulae were counted in a plankton counter tray under a stereo microscope.

In the second experiment the procedure was repeated with planulae of Aurelia aurita. New A. aurita polyps and controls were also used. Differences between treatments and controls were tested by using the non-parametric Mann-Whitney $U$-test (Sokal \& RohIf 1981).

Transplant experiment. A field experiment was carried out (at the same site as that used for sampling) to test the effect of Aurelia aurita polyps on the settling of pelagic larvae (planulae) and juveniles of marine benthic invertebrates.

Glass slides glued to a plastic support leaving an area of $2.5 \times 6.5 \mathrm{~cm}=16.25 \mathrm{~cm}^{2}$ free for larval settlement were used. A total of 30 glass slides, 6 in each treatment, were attached in rows by nylon bolts to 5 grey, opaque PVC plates $(10 \times 45 \mathrm{~cm})$ (Svane 1987). The PVC plates were transplanted to a submerged rack at $5 \mathrm{~m}$ depth in order to allow a natural density of polyps to accumulate (for description of the rack, see Hernroth \& Gröndahl 1983). After $10 \mathrm{~d}$ the plates were brought to the laboratory for analysis. The number and diameter of young polyps on the glass slides were recorded. Enough polyps were then scraped off the glass slides to yield an even distribution of polyps. Four different densities of polyps $\left(600,400,200\right.$ and 100 per $16.25 \mathrm{~cm}^{2}$ slide) were used. As a control, glass slides were also used that had been cleared of polyps and other organisms. The plates were again transplanted to the rack. After $10 \mathrm{~d}$ they were returned to the laboratory, and the number of newly settled and remaining established polyps was recorded. Established and newly settled polyps were distinguished by size difference. During the manipulations, the glass slides with the polyps were kept submerged in seawater and care was taken to avoid mortality due to handling.

The data were statistically evaluated using a 1-way analysis of variance, where density was the main effect. The percentage mortality among the established polyps was arcsine transformed prior to analysis.

Ceramic settling plates $(15 \times 15 \mathrm{~cm})$ were placed at the rack from July to September 1987, in order to study temporal variation in settlement on the hard bottom. From this study more information on the influence of dense covers of Aurelia aurita polyps on settling benthic larvae was gained. Five ceramic plates placed on the rack on 3 July were brought to the laboratory on 
28 July and all settled organisms were recorded. The plates were then returned to the rack together with 2 clean plates. On 27 August, the 7 plates were checked again and returned to the rack with 2 new clean plates. The procedure was repeated on 23 September.

\section{RESULTS}

\section{Predation experiment}

The planula larvae offered to the polyps ranged in size (length $\times$ width) from $220 \times 85$ to $375 \times 125 \mu \mathrm{m}$ for Aurelia aurita planulae and from $175 \times 100$ to $200 \times 110$ um for Cyanea capillata planulae. The polyps, including the tentacles, had a mean diameter of $2.0 \mathrm{~mm}$ and covered large areas of Laminaria saccharina thalli and rock walls (Fig. 2) at the time of the experiment.

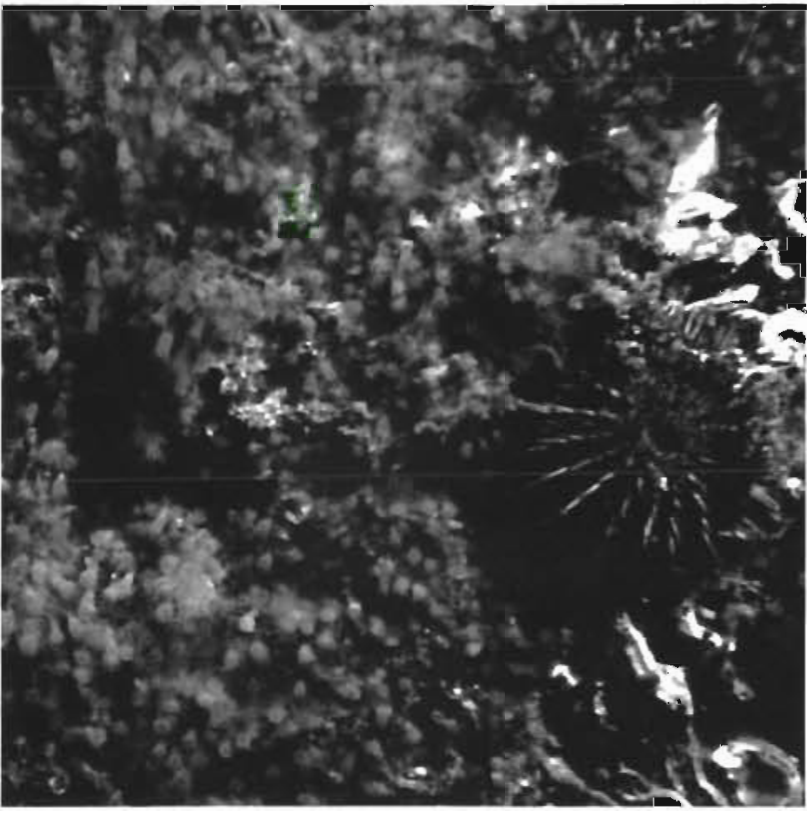

Fig. 2. Dense cover of 4 to $5 \mathrm{~mm}$ tall Aurelia aurita polyps (about $35 \mathrm{~cm}^{-2}$ ) on polychaete tubes and bare rock at $12 \mathrm{~m}$ depth. A sea urchin, Psammechinus miliaris (Gmelin), diameter $25 \mathrm{~mm}$, can also be seen

Survival rates among planulae of Aurelia aurita and Cyanea capillata (in the presence of $A$. aurita polyps) differed significantly (Mann-Whitney $U$-test; $p=0.04$ ). The planula larvae of $A$. aurita showed the higher survival rate between the 2 species. Fig. 3 shows that a significantly higher mortality compared to the controls was observed for both $A$. aurita and $C$. capillata planulae (Mann-Whitney $U$-test; $p=0.02$ and $p=$ 0.008 , respectively).

During the predation experiments it was observed that the surviving planulae of both species metamor-

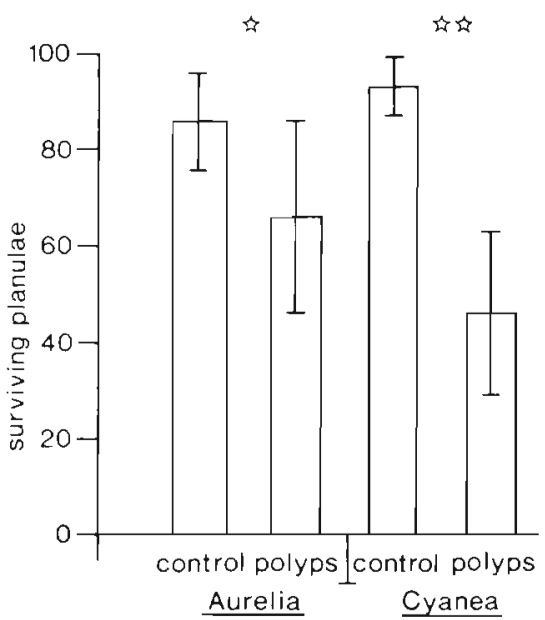

Fig. 3. Mean number of surviving planulae of Aurelia aurita and Cyanea capillata in beakers containing polyps of $A$. aurita, and controls without polyps, after $24 \mathrm{~h}$. Significance levels are given for the effect of treatments using a MannWhitney $U$-test: ( $) p<0.05$, ( $p<0.01$ The $95 \%$ confidence intervals of 6 replicates, each consisting of 100 planula larvae, are also shown

phosed into small polyps in the beakers containing established polyps. This was found only occasionally in the controls.

\section{Transplant experiment}

A natural settlement of organisms (mainly Balanus balanus [L.], Pomatoceros triqueter [L.], Mytilus edulis [L.], Asterias rubens [L.], gastropods and nudibranchs) had appeared on the glass slides after $10 \mathrm{~d}$ at $5 \mathrm{~m}$ depth, but the predominant species to settle was Aurelia aurita. A density of 600 to 700 polyps per glass slide was recorded (40 polyps $\mathrm{cm}^{-2}$ ). The mean diameter of the polyps including the tentacles was $0.62 \mathrm{~mm}$.

Fig. 4 shows the total number of established and newly settled Aurelia aurita polyps on the glass slides after another $10 \mathrm{~d}$. Regardless of the original density of established polyps, the number of polyps reached a mean density of 552 polyps per glass slide.

The numbers of newly settled polyps in the 5 different density treatments are shown in Fig. 4. A significant treatment effect was observed ( $p<0.001, F=45)$, viz. a negative correlation to initial polyp density. In the 0 polyp treatment a mean of 482 newly settled polyps was recorded. A gradual decrease in the number of newly settled polyps was recorded for the 100,200 and 400 treatments. In the 600 polyp treatment a mean of 178 new polyps were found (Fig. 4)

The percentage mortality of the different densities of established polyps is shown in Fig. 5. A significant difference in mortality of the established polyps was 


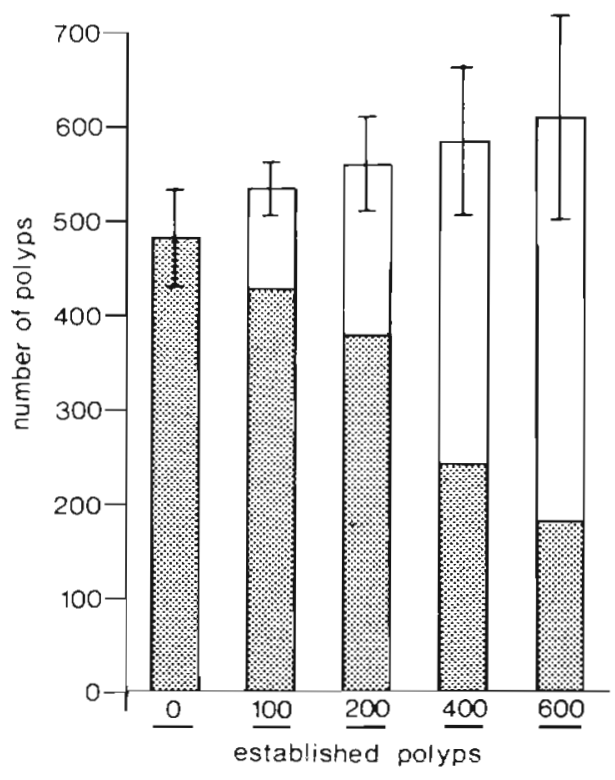

Fig. 4. Aurelia aurita. Mean number of established and newly settled (shaded area) polyps on the glass slides as a function of the original number of established polyps, after $10 \mathrm{~d}$ at $5 \mathrm{~m}$ depth. The $95 \%$ confidence intervals of 6 replicates of each treatment are also shown for the total number of polyps. Effect of treatment on newly settled polyps was tested by using a 1way analysis of variance. Differences between means for treatment were tested with Scheffe's multiple range analysis, and underlined bars show a significant treatment effect

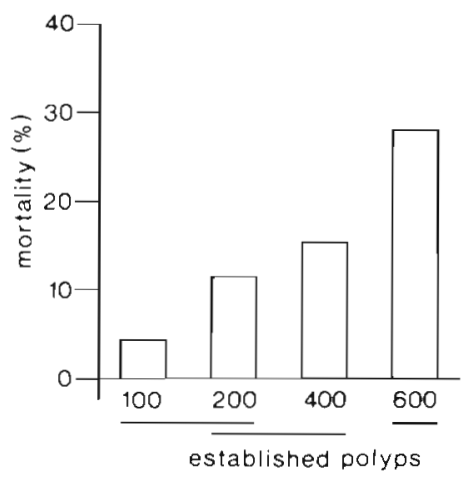

Fig. 5. Aurelia aurita. Percentage of mortality among established polyps as a function of the original number of established polyps after 10 d at $5 \mathrm{~m}$ depth. Effect of treatment was tested by using a 1-way analysis of variance. Differences between means for treatments were tested with Scheffe's multiple range analysis; commonly underlined bars are not statistically different $(p>0.05\}$

found for the different density treatments $(p<0.05$, $F=4$ ). A mortality of $4.5 \%$ was found for the 100 polyp treatment, compared to $28 \%$ for the 600 polyp treatment (Fig 5). The established polyps had increased in size from a mean diameter of $0.62 \mathrm{~mm}$ to $1.29 \mathrm{~mm}$ (including tentacles) during the experimental period.

The results from the experiment with ceramic settling plates revealed the settling and mortality of
Aurelia aurita polyps and other organisms during the longer period from July to September. A mean of $991 \pm 120$ polyps per plate was recorded on 28 July. On 27 August the mean number on the original 5 plates had increased to $5657 \pm 1248$ polyps, but on the 2 plates from 28 July, a mean of 11840 polyps was recorded (53 polyps $\mathrm{cm}^{-2}$ ). When the plates were checked again on 23 September, a mean of $2513 \pm 750$ polyps was recorded on the original plates. On the plates from $28 \mathrm{July}$, a mean of 3617 polyps was left, and on the plates from 27 August, 3867 newly settled polyps were recorded.

\section{Observations of feeding behaviour and settling}

The feeding rate of Aurelia aurita polyps were studied under a stereo microscope. Planula larvae of $A$. aurita and Cyanea capillata were readily eaten by $A$. aurita polyps. Smaller polyps appeared more efficient in capturing planulae. Polyps were capable of capturing the planulae with all parts of their tentacles, and also with their mouth region. When the planulae came in contact with the tentacles, nematocysts were promptly released. At the same time the tentacles were shortened by contraction, and they bent inward and brought the prey toward the mouth. The polyps were able to capture and hold 4 to 6 planulae at the same time. The feeding rate was found to be about 6 planulae per polyp per $h$.

A variety of other organisms were captured and eaten by the polyps, e.g. mussel larvae, gastropod larvae, fish larvae (herring) and copepods (e.g. Calanus finmarchicus, Acartia sp.).

Besides the polyps, Balanus balanus, Pomatoceros triqueter (Polychaeta), Asterias rubens, hydroids and ciliates were the most common settlers on the glass slides and ceramic settling plates. After the establishment of polyps, reduced settling of other organisms was observed on both the glass slides and ceramic settling plates. This was especially true for the high concentration treatments (e.g. 400 and 600 polyps). On the ceramic settling plates, which were submerged for a longer time ( 3 mo) than the glass slides (20 d), predators such as the nudibranch Coryphella verrucosa (M. Sars) settled and consumed polyps (Hernroth \& GröndahI $1985 b)$. The polyps were also removed by the barnacle $B$. balanus and overgrown by a bryozoan (Electra pilosa)

\section{DISCUSSION}

Different stages in the scyphozoan life-cycle (Fig. 6) are exposed to different degrees of mortality. Hernroth \& Gröndahl (1983, 1985a, b) and Gröndahl (1988) found 
that mortality in the polyp and ephyra stages might be important for the regulation of the sexual medusa population. Maintenance and recruitment of marine bottom invertebrates with planktonic larval development and the species ratio of bottom communities depend largely upon the survival-mortality ratio of larvae and early juveniles of these species (Thorson 1946, 1950, Mileikovsky 1974). Thus, a plausible assumption is that mortality earlier in the life-cycle (planulae and polyps) of scyphozoans is more important for the abundance of the medusa population than later (ephyrae and medusae).

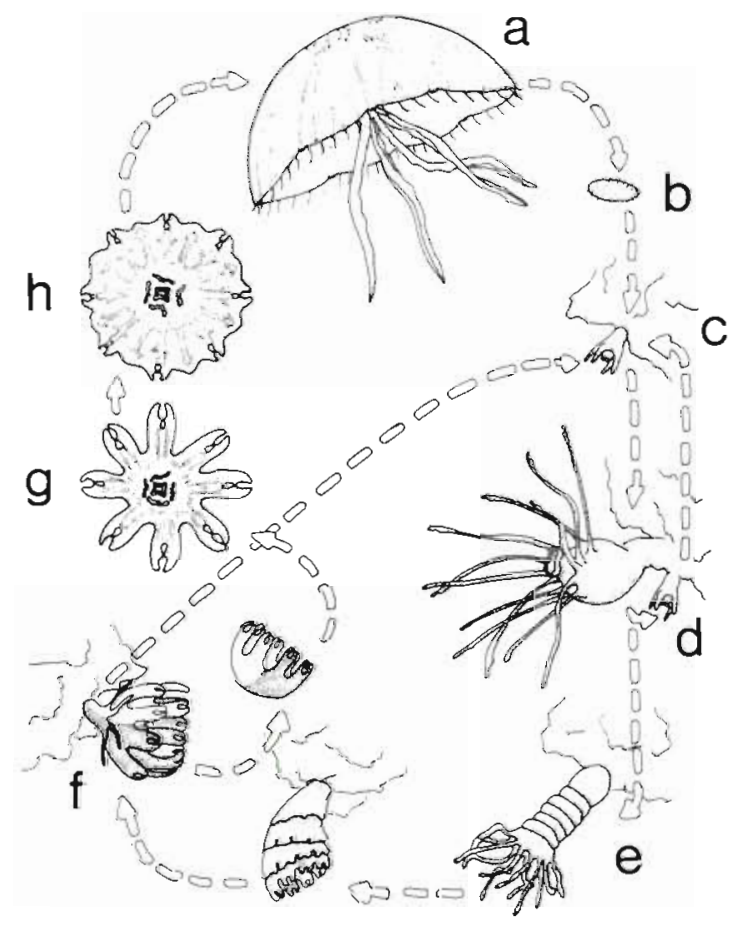

Fig. 6. The life-cycle of a scyphozoan (e.g. Aurelia aurita or Cyanea capillata), including the annual sexual medusa stage and the perennial asexual polyp or scyphistoma stage. The different stages are: (a) medusa, (b) planula, (c) polyp, (d) asexual budding of daughter polyp, (e) strobila, (f) strobilation, (g) ephyra and (h) young medusa

The results from the predation experiments confirmed my previous observations in a preliminary study (Gröndahl 1988), that Aurelia aurita polyps preyed upon planulae of Cyanea capillata in the laboratory (Fig. 3). The results also showed that the polyps were preying upon their own planulae, but to a significantly smaller degree than on planulae of $C$. capillata in the experiments (Fig. 3). When planulae of both species were introduced to the polyps in a Petri dish, the polyps seemed to catch them in equal proportions. The small water volume in the Petri dish and the fact that the planulae were forced toward the tentacles, may, how- ever, give an erroneous impression of the polyps catching ability. The experiment in the beakers probably represented a more natural situation.

Explanations for the higher survival rate among Aurelia aurita planulae might be found in a morphological or behavioural difference between the 2 species. The planula of $A$. aurita has 3 different types of nematocysts compared to only 2 for Cyanea capillata planulae (Widersten 1968). The nematocysts of scyphozoan planulae may function as larval defense against predators. Thus, the extra nematocyst of the $A$. aurita planula might increase the survival rate. Pennington \& Chia (1984) showed that setae of the trochophore larva of the polychaete Sabellaria cementarium function as a larval defense against an array of predators. Other larval defense mechanisms, such as veliger shell, naupliar spines, size of larva and chemical substances, are discussed by Cowden et al. (1984). The predation efficiency of the polyps may be affected by the difference in size and shape between the planula of the 2 species. The greater size of the $A$. aurita planulae compared to $C$. capillata might increase the numerical survival rate of $A$. aurita in the experiments, because a smaller number of planulae would be required to satiate the polyps. A less likely explanation might be that the polyps of $A$. aurita may be selective feeders and have a limited ability to avoid their own larvae. A critical experiment which would determine whether polyps of $A$. aurita do feed selectively in this way would be to introduce a mixture of planulae of both species to the polyps and study the subsequent survival rate.

A problem with studying larval predation in a small beaker of still water is that predator-prey encounters may be influenced by the size and geometry of the beaker and the behaviour of the predator and larvae themselves (Cowden et al. 1984). For example, planulae may remain near the surface or bottom throughout the experiment, encountering the tentacles of the polyps less frequently than would a larva swimming randomly. In my experiments the planulae were released in the center of the beakers and only actively swimming planulae were used, in order to minimize this source of error.

The observation that planulae of both species increased metamorphosis in the presence of polyps of Aurelia aurita may be explained by stimulation of the larvae by the polyps, possibly by way of some released chemical compound. Spangenberg (1968) showed that iodine and thyroxin could induce strobilation in polyps, and Brewer (1978) reported that conspicuous numbers of planulae of $A$. aurita metamorphosed in the presence of a medusa. However, it is not known whether the polyps actually synthesize thyroxin or a related compound (Spangenberg 1968). That tissue extracts may accelerate metamorphosis of conspecific adults in 
higher organisms such as ascidians has been shown by Svane et al. (1987).

The transplant experiments indicate that, independent of the original density of established polyps, the total number of polyps reached a maximum mean density of 552 polyps per glass slide (Fig. 4). This density is in accordance with the maximum densities found on the ceramic settling plates and on natural substrata (Gröndahl 1987). The results showed that the glass slides have a carrying capacity of 30 to 43 polyps $\mathrm{cm}^{-2}$. Glass slides and the ceramic settling plates are flat, smooth areas whereas natural settling substrata (Fig. 2) have a 3-dimensional structure which increases their carrying capacity. The mechanism that maintains this carrying capacity could be that a planula inspects a limited area and avoids previously settled individuals (Brewer 1984). In this way each planula establishes a territory close to, but not touching individuals of its own species. Crisp (1985) described this type of behaviour in the cyprid larvae of barnacles.

Fig. 5. shows that the mortality among established polyps is significantly higher at high densities, suggesting that the polyps are competing for space or food on the glass slides. The polyps could interfere with each other in several ways: (1) the doubling in size from 0.62 to $1.29 \mathrm{~mm}$ in $10 \mathrm{~d}$ which could 'push away' weaker polyps; (2) competition for food resources; and (3) intraspecific aggression between polyps. Purcell \& Kitting (1982) reported intraspecific aggression with fighting tentacles between clones of the sea anemone $\mathrm{Me}$ tridium senile (L.). Other studies demonstrate antagonistic behaviour among neighboring species of corals (Lang 1973, Wellington 1980). However, aggression of this type is unknown among scyphozoan polyps.

It is unlikely that the mortality among established polyps was affected by the presence of other organisms on the glass slides because relatively few other organisms were recruited. The ceramic settling plates on the other hand showed a succession of settlers during the period of July to September, and competitors for space or food, such as barnacles, ascidians, polychaetes and hydroids, may have affected the polyps. In many cases polyps were overgrown by their competitors or consumed by predators such as the nudibranch Coryphella verrucosa (Hernroth \& Gröndahl 1985b).

Fig. 2 illustrates the dense cover of Aurelia aurita polyps on the hard bottom (ca 350000 polyps $\mathrm{m}^{-2}$ ). A logical assumption would be that the polyps may have affected the recruitment of benthic invertebrate larvae (including their own) during their period of peak abundance (July to October). Fig. 4 shows that even a low density of 100 polyps per slide can reduce the settling of new planula larvae. The effect is even more pronounced for the high density treatments (Fig. 4). Results from the predation experiments suggest that predation by the established polyps is a likely explanation for the reduction in settling of planula larvae. Another explanation is that the planulae avoid settling on (or escape from) areas with high conspecific densities. That established polyps also prey on other benthic invertebrate larvae has been observed during this study. The polyps readily eat mussel, gastropod and fish larvae. After the establishment of polyps, a reduced settling of other organisms was observed on both the glass slides and the ceramic settling plates. The importance of benthic invertebrates as predators on planktonic larvae has been discussed by several authors (Korringa 1941, Thorson 1950, Mileikovsky 1974). It is my contention that the Aurelia aurita polyps, which form a dense cover on the hard bottom, play an important role as larval predators during the period July to October in Gullmarsfjorden.

Predation by Aurelia aurita polyps on planulae of Cyanea capillata could be of importance in reguiating the abundance of $C$. capillata polyps in Gullmarsfjorden (Gröndahl 1988); transplant and predation experiments in this study support such a hypothesis. Figs. 4 and 5 illustrate competition for space or food on the substrata available for settling planulae. Thus, if $A$. aurita and $C$. capillata planulae utilize the same substrata and depth ( 1 to $20 \mathrm{~m}$ ) there could be competition between the 2 scyphozoans species. Brewer (1978) and Gröndahl \& Hernroth (1987) reported that C. capillata and $A$. aurita polyps may occur on the same substrata. The planulae of the 2 species also seem to behave similarly prior to settlement (Brewer 1978).

An important question when performing transplant experiments is whether they illustrate actual events in nature. In my experiments I used glass slides that had been preconditioned in seawater and then transplanted to a field rack at $5 \mathrm{~m}$ depth. This was done in order to obtain natural settlement of larvae. Although the glass slides are unnatural substrata, the densities obtained on them were of similar magnitude as on natural substrata such as bare rock or Laminaria thalli. Planula larvae are 'opportunistic' and settle on most substrata $a_{i}$ this is not the case for other larvae. But when comparing settlement on ceramic plates with that upon natural substrata, approximately the same newly settled species were found. Thus, the experiments performed in this study are in good accordance with observed natural events.

The following general conclusions can be drawn from the present work. (1) Aurelia aurita polyps prey on $A$. aurita and $C$. capillata planulae. If such predation occurs in the field, it may have important consequences for the abundance of C. capillata polyps. (2) Competition for space or food is important on the substrata offered to the larvae. (3) Dense covers of A. aurita polyps may affect the recruitment of planktonic larvae 
to hard bottom communities. The results also show the need for further investigations on the interaction between planktonic larvae and the benthic community.

Acknowledgements. I thank F.-S. Chia, Lars Hernroth, Alf Josefson and Ib Svane for valuable discussions. I also thank the director J. O. Strömberg and the staff of the Kristineberg Marine Biological Station for providing excellent working facilities, R. Hessler for linguistic corrections and Ms A. Lilja for the drawing. This project was supported by the Department of Zoology, University of Göteborg, which is gratefully acknowledged.

\section{LITERATURE CITED}

Brewer, R. H. (1978). Larval settlement behaviour in the jellyfish Aurelia aurita (Linnaeus) (Scyphozoa: Semaeostomae). Estuaries 1 (2): 120-122

Brewer, R. H. (1984). The influence of the orientation, roughness, and wettability of solid surfaces on the behaviour and attachment of planulae of Cyanea (Cnidaria: Scyphozoa). Biol. Bull. mar. biol. Lab., Woods Hole 166: 11-21

Cowden, C., Young, C. M., Chia, F. S. (1984). Differential predation on marine invertebrate larvae by two benthic predators. Mar. Ecol. Prog. Ser. 14: 145-149

Crisp, D. J. (1985). Recruitment of barnacle larvae from the plankton. Bull. mar. Sci. 37 (2): 478-486

Crowe, W. A., Josefson, A. B., Svane, I. (1987). Influence of adult density on recruitment into soft-sediments: a shortterm in situ sublittoral experiment. Mar. Ecol. Prog. Ser. 41 (1): 61-69

Gröndahl, F., Hernroth, L. (1987). Release and growth of Cyanea capillata (L.) ephyrae in the Gullmar Fjord, western Sweden. J. exp. mar. Biol. Ecol. 106: 91-101

Grondahl, F. (1988). A comparative ecological study on the scyphozoans Aurelia aurita, Cyanea capillata and Cyanea lamarckii in the Gullmar Fjord, Western Sweden, 1982-86. Mar. Biol. 97: 541-550

Hernroth, L., Gröndahl, F. (1983). On the biology of Aurelia aurita (L.) 1. Release and growth of Aurelia aurita (L.) ephyrae in the Gullmar Fjord, Western Sweden, 1982-83. Ophelia 22 (2): 189-199

Hernroth, L., Gröndahl, F. (1985a). On the biology of Aurelia aurita (L.): 2. Major factors regulating the occurrence of ephyrae and young medusae in the Gullmar Fjord, Western Sweden. Bull mar. Sci. 37 (2): 567-576

Hernroth, L., Gröndahl, F. (1985b). On the biology of Aurelia aurita (L.). 3. Predation by Coryphella verrucosa (Gastropoda, Opisthobranchia), a major factor regulating the development of Aurelia populations in the Gullmar Fjord, Western Sweden. Ophelia 24 (1): 37-45

Jägersten, G. (1968). Livscykelns evolution hos Metazoa.
Scandinavian University Books, Sweden, Läromedelsförlaget Stockholm, Göteborg, Lund

Keough, M. J., Downes, B. J. (1982). Recruitment of marine invertebrates: the role of active larval choices and early mortality. Oecologia (Berl.) 54: 348-352

Korringa, P. (1941). Experiments and observations on swarming, pelagic life and settling in the European flat oyster, Ostrea edulis L. Archs néerl. Zool. 5: 1-249

Lang, J. (1973). Interspecific aggression by scleractinian corals. 2. Why the race is not only to the swift. Bull. mar. Sci. 23: $260-279$

Lindahl, O., Hernroth, L. (1983). Phyto-zooplankton community in coastal waters of Western Sweden - an ecosystem off balance? Mar. Ecol. Prog. Ser. 10: 119-126

Mileikovsky, S. A. (1974). On predation of pelagic larvae and early juveniles of marine bottom invertebrates by adult benthic invertebrates and their passing alive through their predators. Mar Biol. 26: 303-311

Möller, H. (1980). Population dynamics of Aurelia aurita medusae in Kiel Bight, Germany (FRG). Mar. Biol, 60: $123-128$

Pennington, J. T., Chia, F. S. (1984). Morphological and behavioral defenses of trochophore larvae of Sabellaria cementarium (Polychaeta) against four planktonic predators. Biol. Bull. mar biol. Lab., Woods Hole 167: 168-175

Purcell, J. E., Kitting, C. L. (1982). Intraspecific aggression and population distributions of the sea anemone Metridium senile. Biol. Bull. mar. biol. Lab., Woods Hole 162: 345-359

Sokal, R. R., Rohlf, F. J. (1981). Biometry, 2nd edn. W H. Freeman \& Co., San Francisco

Spangenberg, D. B. (1968). Recent studies of strobilation in jellyfish. Oceanogr. Mar. Biol. A. Rev. 6: 231-247

Svane, I. (1987). On larval behaviour and post-metamorphic mortality of Ascidia mentula O. F. Müller. Ophelia 27 (2): $87-100$

Svane, I., Havenhand, J. N., Jørgensen, A. J. (1987). Effects of tissue extract of adults on metamorphosis in Ascidia mentula O. F. Müller and Ascidiella scabra (O. F. Müller). J. exp. mar. Biol. Ecol. 110: 171-181

Thorson, G. (1946). Reproduction and larval development of Danish marine bottom invertebrates, with special reference to the planktonic larvae in the Sound (Oresund) Meddr Danm. Fisk.-og Havunders. (Ser. Plankton) 4 (1): $1-523$

Thorson, G. (1950). Reproduction and larval ecology of marine bottom invertebrates. Biol. Rev. 25: 1-45

Watzin, M. C. (1986). Larval settlement into marine softsediment systems: interactions with the meiofauna. J. exp. mar Biol. Ecol. 98: 65-113

Wellington, G. M. (1980). Reversal of digestive interactions between Pacific reef corals: mediation by sweeper tentacles. Oecologia (Berl.) 47: 340-343

Widersten, B. (1968). On the morphology and development in some cnidarian larvae. Zool. Bidrag. Uppsala 37: 139-182 